beginning; and that the ratio of mortality in those cases was more than double that in the cases treated by myself.

The establishment of the first point in question renders the establishment of the second a matter of inferior moment. Indeed, were it possible to bide from one's-self the conviction that the mortality in small-pox is at least doubled by improper treatment, or the neglect of all medical treatment whatever; were it even credible, after what has been ascertained to the contrary, that smallpox is beyond the art of medicine, either to control or cure, the algument would only gather strength therefrom, for timely and universal vaccination; seeing that we have here an incurable, an intractable, disease; and here, also, a mean of preventing the occurrence altogether of that disease, which, when it does occur, can neither be controlled no: cured, it becomes indisputably our duty to employ the preventive. The only preventives of small-pox are small-pox and vaccination. Small-pox, employed as a preventive, only secures the individual by endangering the community-vaccination secures the community by preserving the individual. Let us hope that the land which gave birth to vaccination will not suffer the lapse of half a century from the date of its discovery before guaranteeing to its every inhabitant the full benefit of its application. But vaccination, to be effectual, must be general; and vaccination, to be of general benefit, must be of imperative obligation. And the lesson taught by the small-pox epidemic of the past and present years ought not to be suffered to pass without conveying all the instruction it contains to the Government and people of England. A series of statistical reports on the subject, from every parish in England, ought to be moved for in Parliament; and an inquiry, founded upon the facts and figures afforded by these reports, should be fearlessly instituted; and, arising out of that inquiry, a law should be devised, not for the increase of Ephesian craftsmen's gains-not for the addition to chartered monopolists of wealth and place and patronage -but a law, large, liberal, and worthy of a great, a glorious, and a free people; a law of condescension, stooping to apprehend the case of the meanest, and to provide for the wants of the poorest; but a law of comprehension as well, spreading wide its arms throughout the length and the breadth of the whole British empire, to maintain the blessings of health and life and beauty among tens of millions of our own name and nation, and among hundreds of millions of our fel. low men and fellow subjects, of all colours and of all climes.

\footnotetext{
6, Cheyne-row, Chelsea, Sept. 1, 1339.
}

\section{ARTHRITIC IRITIS.}

\section{To the Editor of THE LANCET.}

Sin:-The following case of arthritic iritis, terminating in total blindness, in which useful vision was afterwards restored, is very much at your service. I remain, Sir, your obedient servant,

$$
\begin{array}{r}
\text { R. DAvis, } \\
\text { 1, City-road, Finsbury-square. }
\end{array}
$$

R. Davis, Surgeon.

S. H., aged 40, a master carpenter, residing in the City-road, states, that about sixteen weeks ago from the present date (Sept. 1st, 1839) he was afflicted with a severe attack of inflammation of the right eye, which compelled him to seek medical advice. He is a man rather beneath the middle stature, of sallow complexion, of spare and scrofulous habit, with dark hair, and brown eyes. He further states that he has been indisposed for nine months previous to his eye becoming affected, in consequence of an attack of rheumatic fever; and that he has not had syphilis for the last fourteen years.

The eye not improving under the treatment adopted, and his vision becoming seriously affected, he was advised by his friends to apply for relief at that very excellent and useful institution, the Ophthalmic Hospital, in Moorfields. The benefits and blessings conferred upon society by that institution are incalculable, and the pains and trouble which are taken by the medical officers in teaching ophthalmic surgery, deserve the highest praise. He was there cupped, leeched, and blistered, and underwent various other kinds of treatment, for six weeks, without benefit. He was now advised, by a patient of mine, to apply to me. I saw him, for the firsi time, on the 2nd of July last; he was then completely blind. He complained of a constant, deepseated pain in the right temple, which had continued for some considerable time before he applied to me, giving rise to the supposition, at the institution, that inflammation of the internal tunics and amaurosis existed; it was written so on his paper. The eye presented the following appearance: conjunctiva red, loose, and llabby; superficial vessels full, tortuous, and in a state of relaxation; iris covered with tubercles of lymph, and of a dirty.buft colour; pupil very much contracted, in the centre of which there is a mass of $l y m p h$, to which the pupillary margin of the iris is adherent. There was, also, profuso lachrymation. The indications to be fulfilled in this case were, to reliere pain (the pain of his head being so severe at night as to prevent sleep); to prevent further mischief from inflammation, by arresting the effusion of Iymph; to break down adhesions, and to dilate the pupil, and to rally the powers of his constitution, 
his pulse being feeble and weak, in consequence of his previous illness, and the treatment to which he had been lately subjected. I, therefore, ordered that his temple should be rubbed night and morning with an ointment consisting of mercurial ointment and opium, for the purpose of relieving pain; that belladonna should be applied to the eyebrow, to produce dilatation of the pupil ; that five grains of Plummer's pill should be taken night and morning, to improve the secretions, and to cause absorption of lymph; and that he should take half a drachm of carbonate of iron, three times a day, to strengthen him.

July 6. No improvement; pain still continues.-Blister to the temple; ung. lyttæ, to keep the blister open. Let two leeches be applied, and let the other remedies be persevered in.

10. Feels less pain in the temple; has been much fatigned during the last two days; thinks he can see a little; pupil still in statu quo.

14. Remedies continued.

18. Less pain in the head, the blister being healed.-Let the tartar emetic ointment be applied until pustules are produced on the temple. Continue the other remedies.

22. Much the same.-Apply two leeches.

28. Two large and angry-looking pustules on the temple; iris improved in colour; pupil dilating, the adhesions giving way; can now distinguish objects.-Continue the remedies.

Aug. 2. Vision very much improved; can count the fingers on the hand when held up; adhesions rapidly giving way; pupil dilated and irregular ; iris nearly of the same colour as that of the other eye.-Continue the remedies, and let the tartar emetic ointment be left off.

7. Examined the eye to-day with a powerfullens; saw the adhesions binding the iris to the capsule of the crystalline lens ; capsule itsulf opnque, consequently, vision in the eve affected will never be so good as in the other; no redness of conjunctiva or sclerotic; says he can see nearly as well as ever.-Continue the remedies.

14. Iris of the natural colour; pupil much dilated and circular.

16. Vision very good; pupil circular, and sensible to the stimulus of light. Tired of physic; wishes to discontinue; granted.

This case is valuable on two accounts; in the first place, it teaches the necessity of never despairing of doing good in cases of iritis, even should blindness exist,-a rule forcibly inculcated by all the best writers on ophthalmic surgery; and, in the second place, it points out the necessity of enforcing the regular attendance of patients, and taking care to see the remedies put into execution, a circumstance too often neglected by patients if left to themselves (hence the reason of so many complaints amongst the out-pa- tients of our hospitals and public institutions), for, in my humble opinion, the favourable result of this case entirely depended upon the above-mentioned cause.

September 1st, 1839.

CALCULUS IN THE FEMALE.

EMPLOYMENT OF THE BISTOURIE CACHÉE.

To the Editor of THE LANCET.

SIR:-As calculus in the female is of rare occurrence, and as the following operation for its removal is extremely simple and safe, I have considered it my duty to record it. I must, in justice, state that a distinguished surgeon, Mr. Hodgson, was the first who adopted the practice of using the bistourie cachée, before introducing Weiss's dilator.

I forward the case for insertion in your valuable Journal, and am, Sir, your obedient servant,

12, Old-square, Birmingham

Pye Henry Chavasse. Sept. 5, 1839 .

July 25, 1836. Mrs. Mills, ætat. 45, a washerwoman, has been afficted with stone in the bladder for twelve months. She, at times, suffers most severely; so much so that the strongest opiates will not relieve her, and she is brought into such an ill state of health that she is incapable of following her employment. After sounding her and ascertaining the presence of the stone, I proposed an operation, to which she gladly acceded; and on August 2nd, 1836, I performed it, assisted by $\mathrm{Mr}$. Bindley, an intelli gent surgeon of this town. A door was laid on the bed, and covered with sheets, upon which she was placed and secured in the same manner as for lithotomy. After sounding her again, " to make assurance doubly sure," I introduced the bistourie cachee in the urethra, and then drew it out cutting obliquely upwards and dividing the mucous membrane and muscular fibres of the canal, for about two or three lines. Having withdrawn the bistomie I then irtroduced Weiss's female dilator, and gently turned the screw, allowing a few moments to elapse between each turn. After about a quarter of an hour's cautious dilatation $I$ found there was sufficient room to introduce a good-sized pair of forceps; and with a little care I was enabled to extract a calculus of the size of a large pigeon's egg, and of the weight of six drachros and a half. On examining its chemical composition it was found to consist chiefly of phosphate of lime. She rapidly recovered from the operation.

After the operation the urine was thick, and of a milky appearance, but it soon became clear under the administration of the ollowing mixture :- 